\title{
Controlar al extranjero Lecturas en clave antropológica
}

\section{Controlling Migrants: Anthropological Perspectives Controle de estrangeiros: leituras antropológicas}

doi: 10.34096/runa.v41i1.8124

Nota de los editores del dossier: Agradecemos a Brenda Canelo y Sandra Gil Araujo por sus aportes a las reflexiones vertidas en esta presentación.

Este dossier reúne una serie de artículos que analizan, en clave antropológica, una faceta ineludible de los procesos migratorios contemporáneos: las formas de su regulación, vigilancia y control que resultan de acciones, omisiones y efectos de Estado.

En el campo de los estudios migratorios, desde fines del siglo $\mathrm{XX}$, diversos textos señalan insistentemente la creciente tendencia de los Estados a regular los movimientos poblacionales desde perspectivas restrictivas, selectivas y securitistas que dificultan o impiden el cruce de fronteras internacionales de millones de personas que se desplazan por motivos económicos y/o por necesidades de protección (Castles, 1997 y 2008; Arango, 2003; Organización de Naciones Unidas [ONU], 2016, entre muchos otros).

Ahora bien, esta regulación de los intensos movimientos migratorios contemporáneos se instala en la actualidad en un escenario de complejos procesos globales y regionales. Mencionamos dos en particular, de escalas y dinámicas disímiles pero de previsibles sinergias: el que en 2018 condujo a la firma e incipiente implementación del Pacto Global para una Migración Segura, Ordenada y Regular, y el avance de gobiernos neoliberales y conservadores en varios países. El primero presupone que las migraciones, si no se gestionan adecuadamente, generan desorden, irregularidad ("ilegalidad") e inseguridad. Bajo este marco -en el que se combina cierta atención a estándares de derechos humanos con intereses laborales globalizados (Sassen, 2013)- se han fraguado nociones tales 
como gobernabilidad migratoria y responsabilidades compartidas, que motorizan el involucramiento de los países de origen y tránsito en el control migratorio, de modo de reducir la cantidad de personas que efectivamente logran arribar a las fronteras del país al que desean ingresar. Así, la idea de gobernanza de las migraciones acentúa el uso de acuerdos y tratados internacionales como forma de ordenar los flujos de personas y de facilitar a los Estados la imposición (y naturalización) de exigencias de "legalidad"/regularidad, en un giro político que desplaza del debate público la concepción de la migración como un derecho humano. El segundo escenario es relevante porque serán estos gobiernos neoliberales y conservadores los que se decidan más explícitamente por determinadas (y costosas) tecnologías y prácticas de control que tendrán efectos concretos en las vidas y derechos de las personas migrantes, refugiadas y solicitantes de asilo, entre los que se incluyen mantenerlas "atrapadas en la movilidad", detenidas por tiempo indefinido en un lugar del tránsito migratorio (Odgers y Campos 2014).

Gran parte de los trabajos contemporáneos de revisión crítica y situada del conjunto de normas, prácticas, narrativas y discursos en torno al control de las migraciones se encuadran, así, en el actual contexto de reordenamiento de lo que se ha dado en llamar "regímenes" migratorios y de fronteras. En términos generales, la noción de régimen no alude a un campo de estudios acotado, sino que es tributaria de diversas tradiciones teóricas y metodológicas provenientes de las relaciones internacionales, las políticas sociales y los estudios de la gubernamentalidad (Foucault, 2006; Gil Araujo, 2010; Horvath, Amelina y Peters 2017). Entendida como conjuntos de redes, reglas, prácticas, procedimientos, discursos, actores y tecnologías que regulan y dan sentido a acciones y comportamientos concretos y situados, la perspectiva de régimen involucra la combinación de investigación etnográfica, análisis del discurso, de fuentes documentarias y jurídicas y una mirada atenta a las dimensiones de lo macro.

Aplicada a la movilidad, a las migraciones internacionales y a las fronteras, esta perspectiva permite observar las formas particulares que adquieren las relaciones entre migraciones y control en el marco del sistema capitalista (Mezzadra, 2013). Supone no solo centrar "la atención sobre el papel de los distintos Estados y de las cambiantes administraciones regulatorias y de vigilancia que afectan a la movilidad" (Glick Schiller y Salazar, 2013, p. 189), sino también incluir una multiplicidad de actores y prácticas no estatales que se relacionan entre sí y con las agencias de control sin estar organizados a partir de lógicas burocrático-racionales. Así, la noción de regímenes migratorios y de fronteras permite analizar al Estado desde una perspectiva amplia-como un conjunto de relaciones sociales y de poder- y entender a la enorme gama de regulaciones destinadas a la población extranjera como efecto de prácticas sociales desiguales. Por ello, la noción de regímenes migratorios visibiliza y permite registrar los discursos y las prácticas (a menudo conflictivas entre sí) de numerosos actores, diferentes y desiguales.

Sabine Hess (2012) argumenta que son muchos los actos y discursos involucrados en la construcción de las formas de ver y entender las migraciones y sus fronteras (físicas, jurídicas, clasificatorias y simbólicas). Entre ellos debe incluirse el impacto de las investigaciones académicas en la (re)construcción de las categorías utilizadas por las instituciones gubernamentales, ya que los actos científicos son también actos políticos. Los regímenes migratorios, fronterizos y de control poblacional de extranjeros deben pensarse simultáneamente desde lo regulatorio y lo performativo, puesto que las negociaciones 
conflictivas entre múltiples actores catalizan nuevos territorios económicos, sociales y de subjetividades que caen bajo el paraguas de la "gobernabilidad de los procesos migratorios".

\section{Mientras tanto, en América Latina...}

En el contexto latinoamericano, estas perspectivas están presentes pero han tenido impacto dispar. Puesto que la región exhibe patrones migratorios históricos propios y distintivos, así como procesos de integración regional que incluyen ámbitos intergubernamentales abocados a cuestiones relativas a la movilidad, ni las dinámicas ni las preocupaciones de las instituciones pueden ser pensadas linealmente desde las agendas del norte global-como tampoco pueden/deberían serlo las agendas de investigación.

En lo que respecta a las dinámicas, para fines del siglo XX las migraciones intrarregionales se habían consolidado como "uno de los rasgos dominantes, vigentes y de importante cuantía" (Comisión Económica para América Latina y el Caribe [CEPAL], 2018, p. 10) de los movimientos de población en América Latina. Efectivamente, desde la década de 1970, en las migraciones intrarregionales han predominado los movimientos entre países vecinos: desde Haití hacia República Dominicana, desde el triángulo norte hacia México, desde Colombia hacia Venezuela, desde Paraguay y Bolivia hacia Argentina, desde Perú hacia Chile (por mencionar algunos) y, a partir de 2015, importantes movimientos desde Venezuela hacia Colombia, Ecuador, Panamá, Perú, Chile, Argentina, Brasil y México. Por otro lado, varios países de América Latina y el Caribe presentan dinámicas de emigración extrarregional (principalmente hacia Estados Unidos), y en todos los países de origen existen retornos (voluntarios o forzosos) de emigrantes regionales y extrarregionales. En cuanto a los procesos de integración regional, la Comunidad Andina, el Mercosur y la UNASUR incluyeron la movilidad transfronteriza en sus agendas de trabajo multilaterales. El mayor logro en este sentido ha sido el Acuerdo de Residencia entre los Estados Parte del Mercosur y Asociados, que de diversas maneras ha incidido en las normas y en las prácticas migratorias regionales.

No obstante, en los últimos años, la región ha comenzado a presenciar lo que los organismos internacionales han dado en llamar "grandes movimientos de migrantes y refugiados", donde grande describe no tanto a la cantidad de personas que se desplazan como el contexto geopolítico, "la capacidad de respuesta de los Estados receptores y el efecto que ocasionan en el país de destino por su carácter repentino o duradero" (ONU, 2016). Ejemplos han sido los desplazamientos de adolescentes no acompañados desde Honduras, El Salvador y Guatemala hacia EE.UU y las "caravanas migrantes" que recorren México. Por la tradición social y política de la región, estos movimientos han tendido a ser encuadrados (con tensiones) dentro de lógicas de migración y derechos, más que en las perspectivas de migración y desarrollo que dominan en el norte global. Otro "gran movimiento" consiste en los casi 4.000.000 de venezolanos/as que han arribado en los últimos cinco años a países de la región (R4V, Organización Internacional para las Migraciones y Alto Comisionado de las Naciones Unidas para los Refugiados, 2020), lo cual ha generado enormes desafíos políticos, regulatorios, administrativos y humanitarios que han tornado la movilidad venezolana en un tópico de las agendas regionales y nacionales de América Latina y el Caribe. 
Al igual que en otras partes del mundo, en América Latina, las normativas migratorias restrictivas y las prácticas estatales de control de fronteras y de permanencia han alentado el surgimiento de agentes que ofrecen medios para sortear obstáculos al ingreso o a la residencia, y que lucran así con la población en movilidad. En tanto las normas y prácticas estatales tienden a colocar en un lejano segundo plano el bienestar y los derechos de las personas migrantes, refugiadas y solicitantes de asilo, en las últimas décadas han adquirido mayor presencia organizaciones locales sin fines de lucro abocadas a la asistencia y protección de personas cuya situación de movilidad internacional las ha vuelto circunstancialmente vulnerables o ha generado un menoscabo en su acceso a derechos. Organizaciones de derechos humanos, equipos de abogados/as, organizaciones de migrantes y movimientos sociales buscan incidir tanto en los grandes rumbos regionales como en las pequeñas prácticas locales. Asistimos hoy a la consolidación de una variada serie de actores que intervienen en contextos de control migratorio y de control y regulación poblacional cuyas características urge analizar (Jardim, 2017).

Debido a las dinámicas migratorias y políticas apretadamente resumidas arriba, es posible pensar que, en América Latina, se encuentran en curso modificaciones de diverso alcance de los regímenes migratorios y de fronteras. Algunos autores sostienen que la dinámica globalizadora ha reconfigurado el modo de gobernar las migraciones, para dar lugar a la construcción de un nuevo régimen global de control de las migraciones internacionales cuyos rastros recientemente han comenzado a verse en nuestros países (Düvell, 2003; Domenech, 2013).

\section{En clave antropológica}

En las teorizaciones hegemónicas sobre migraciones, la incorporación del Estado como actor de peso fue una deuda que comenzó a saldarse hace unas pocas décadas. Si la antropología ha demostrado ser muy fructífera para esclarecer lógicas y operatorias de Estado (Trouillot, 2001; Das y Poole, 2004; Shore, Wright y Però, 2011), lo ha sido especialmente en su cruce con las poblaciones migrantes. Ejemplos claros remiten a la mismísima instalación de la dicotomía nativo-extranjero, que ha sido central en la construcción de las naciones como Estados (Sayad, 2008) y, más concretamente, a la hora de mirar cómo impactan las normas y las prácticas estatales en las trayectorias de las personas migrantes (Pita y Pacecca, 2017). Y también al momento de observar la relación de los/las migrantes con el Estado, es decir, cómo se mueven en y a través de instituciones estatales (Canelo, 2012; Jardim, 2017).

Como hemos señalado, aunque América Latina ha sido frecuentemente destacada en el ámbito internacional por haber realizado algunos esfuerzos puntuales para la regularización y protección de los derechos de la población migrante, la coyuntura actual se caracteriza por el auge de las narrativas antiinmigrante, el fortalecimiento de las agendas conservadoras y neoliberales en varios países de la región y los crecientes obstáculos a la regularización y al acceso a derechos de personas migrantes, refugiadas y solicitantes de asilo. En este contexto, ¿cómo encarar un quehacer antropológico crítico en el cual la decisión misma de qué investigar y cómo hacerlo esté atravesada por la ética del acompañamiento y compromiso? ¿Cómo incidir en agendas estatales e interpelar a las poblaciones "nativas" en momentos en que peligra la misma vida de los/las migrantes? ¿Alcanza con producir y difundir datos, o precisamos nuevas maneras de comunicar nuestros estudios para alterar la 
deshumanización del otro? ¿Qué interseccionalidades impulsan solidaridades en contextos de restricción de derechos? La ola feminista contra las violencias de género que recorre los movimientos sociales y políticos de la región ¿puede iluminar la presencia de mujeres y niñas migrantes, abriendo oídos, generando solidaridades y sororidades? La agobiante evidencia en relación con la niñez pobre, con acceso limitado a educación y salud, ¿puede recuperar las trayectorias migratorias de cientos de miles de familias, niños, niñas y adolescentes?

Teniendo presente que el prejuicio genera sordera en buena parte de las audiencias a las que quisiéramos llegar, no debemos desatender el potencial de interpelación que anida en la interdisciplinariedad, especialmente en el cruce con las artes. Producir documentales o películas; recoger y difundir expresiones de arte verbal, poesía, literatura y música producida por migrantes; recurrir a performances o a instalaciones; montar obras de teatro sobre temáticas migratorias con participación de personas y colectivos migrantes son algunas vías posibles para ampliar el registro y el alcance de las narrativas de igualdad.

A partir de experiencias de investigación, participación, acompañamiento y/o apoyo de organizaciones de migrantes en diversos países de América Latina, el núcleo de este dossier reflexiona acerca de los desafíos de un quehacer antropológico comprometido con el desarrollo disciplinar crítico y con la defensa de derechos. Los artículos aquí incluidos analizan el accionar de individuos, instituciones, situaciones y eventos muy diversos ocurridos en Argentina, Brasil, México y Uruguay, y muestran la complejidad de las migraciones internacionales contemporáneas, algunas de cuyas facetas se conectan de manera estrecha y evidente -especialmente en las fronteras- en tanto que otras lo hacen de manera más difusa, como, por ejemplo, los controles o regulaciones destinados a poblaciones etnicizadas y racializadas.

En el contexto argentino, signado tanto por la vigencia de una ley migratoria pionera en la introducción de una perspectiva de derechos (que data de 2004) como por el avance de tendencias coercitivas en la política urbana, Sofía Silva y Stella Maris García muestran formas de control estatal sobre la presencia de los/las migrantes "andinos/as" en la ciudad de La Plata. Para ello, describen y analizan interacciones entre asociaciones de migrantes y agentes municipales en torno a celebraciones andinas, en una disputa por el espacio urbano y el derecho a la ciudad que involucra sentidos de estar en el mundo y de significar el territorio. La disputa de "territorialidad" es eje de un conflicto entre la idea de ciudadanía estatal y modos de inscripción de "otras" maneras de existencia por parte de inmigrantes en distintas generaciones.

Cruzando el Río de la Plata, el trabajo de Pilar Uriarte Bálsamo propone una mirada sobre las políticas migratorias de otro de los países cuya ley de migraciones suele presentarse, junto con la argentina, como modelo elogiable por su perspectiva de derechos: Uruguay. La autora resalta la articulación conflictiva de una serie de dispositivos universalizantes y homogeneizadores (encarnados en el énfasis en el acceso a la documentación de las personas migrantes) con otros restrictivos y excluyentes (tales como las exigencias de visados y la militarización de fronteras). Sobre este campo etnográfico singular, invita a observar las operatorias de folclorización y racialización de la población migrante y a analizar modos de exclusión en el corazón de las propias herramientas de "integración" que podrían imaginar una universalización del derecho como ciudadanos, tan caro a los ideales nacionales. 
Silvia Zelaya nos lleva, a partir de su trabajo de campo, a la Primera Conferencia Nacional de Migraciones y Refugio de Brasil (2014), un encuentro convocado por instancias de gobierno con el fin de reunir aportes de distintos sectores de la sociedad, incluidas las organizaciones de migrantes, para el diseño de lo que sería una nueva política migratoria. Allí, releva ciertas prácticas institucionales que identifica como tecnologías de control sobre la población migrante, operantes en el proceso mismo de actualizar la normativa migratoria -proceso que resultó en la sanción de la Ley de Migración de 2017- en un marco declaradamente democrático.

Desde la frontera norte de México, Iban Trapaga explora, bajo el prisma de la biopolítica, documentos sociocientíficos y mediáticos locales que tematizan la figura del migrante. En una suerte de coincidencia tristemente contemporánea de la COVID-19, analiza la construcción discursiva del migrante como pandemia. Sostiene que, performativamente, los discursos de peligrosidad y contaminación que atraviesan el cuerpo migrante lo sujetan a dispositivos de seguridad, prácticas de encierro y segregación espacial, y también, al más clásico ejercicio del derecho soberano del Estado a la vida y a la muerte.

El dossier cierra con el artículo invitado de Barak Kalir, que ofrece una mirada sobre y desde el norte global, provechosa por cuanto permite anticipar los alcances de esas prácticas burocrático-administrativas inspiradas en políticas de corte securitista que han (re)despegado en materia migratoria en América Latina. El autor nos instala frente al escenario de los regímenes migratorios opresivos que los Estados liberales occidentales han implementado en décadas recientes por medio del uso masivo de la detención y deportación de personas migrantes del "Tercer Mundo", por ellos mismos "ilegalizadas". La puesta en foco de la dimensión racializadora/racista de estas políticas y prácticas y el énfasis en su continuidad respecto de las ideologías y técnicas de gobierno coloniales -en particular, en lo referido a la gestión de la espacialidad-ilustran, una vez más, la potencia crítica y el potencial holístico de la antropología para vincular fenómenos sociales que se despliegan en distintos niveles y que involucran a actores muy diversos. El acto científico-político de denominar -o de llamar las cosas por su nombre: departheid, en este caso- abre el camino para una "política de la vergüenza" que interpele a quienes sostienen y apoyan tales regímenes y alerte a quienes, desde una postura de derechos, intervienen intentando humanizar estas prácticas y mitigar sus efectos.

Más allá de sus diferencias en cuanto a fuentes y casos, estos trabajos proponen modos de abordar las migraciones internacionales contemporáneas en clave antropológica y se interrogan acerca de los límites y dificultades para hacer etnografías sobre y con migrantes a partir de experiencias diversas y/o multilocales de investigación que, entre otras cuestiones, visibilizan sujetos, actores y alianzas ya conocidos así como otros novedosos o inesperados. Los textos enfatizan el carácter heterogéneo y fragmentario del Estado, y revelan grietas, resquicios y fracturas que representan oportunidades para la resistencia a los obstáculos burocráticos y para la construcción de prácticas solidarias críticas, ya sea a niveles locales, nacionales o regionales. Así, al igual que muchos otros, estos estudios se esfuerzan por construir un saber "para" los/las migrantes -generalmente trabajando codo a codo en sus asociaciones, con referentes o líderes migrantes- y de poner a disposición descripciones, análisis y reflexiones sobre el funcionamiento de ciertos organismos de control del Estado. 
Todas estas son líneas de investigación que involucran activamente el compromiso de investigadores e investigadoras y trabajan para construir lazos entre las agendas académicas y las inquietudes, demandas y preocupaciones de las personas migrantes y de las organizaciones que las convocan y representan. Pero el horizonte de desafíos es largo. Muchas organizaciones y referentes migrantes demandan más a los/as antropólogos/as (y a las ciencias sociales en general): nos piden que no "hablemos por ellos/as" y nos interpelan para hacerles partícipes de los recursos (cada vez más escasos) disponibles para la investigación. En este sentido, un compromiso más cabal y fructífero debe partir del reconocimiento de que los/las migrantes son grandes hermeneutas, y que son tan productores de conceptos y teorizadores de las migraciones como los/las investigadores/as. Un posible camino para ello -y una agenda regional propia- consiste en echar mano de la importante tradición de investigación colaborativa latinoamericana que equipara el estatus de los saberes -la investigación-acción participativa de Orlando Fals Borda, la antropología social de apoyo de Adolfo Colombres, la educación popular de Paulo Freirey traerla al campo migratorio en este contexto de creciente restricción de la circulación internacional de personas y de limitación de derechos de los/las migrantes, tan funcionales al capitalismo actual. 


\section{Q Referencias bibliográficas}

» Arango, J. (2003). Inmigración y diversidad humana. Una nueva era en las migraciones internacionales. Revista de Occidente, 268, 5-20.

"Canelo, B. (2012). Migración y disputas espaciales en la Ciudad de Buenos Aires. Buenos Aires: Antropofagia.

»Castles, S. (1997). Globalización y migración: algunas contradicciones urgentes. Texto del discurso inaugural presentado en la reunión del Consejo Intergubernamental del Management of Global Transformation Programmes (MOST), UNESCO, 16 de junio.

"Castles, S. (2008). Understanding Global Migration: A Social Transformation Perspective. Conference on Theories of Migration and Social Change. St Anne's College, Woodstock Road, Oxford, martes 1 - jueves 3 de julio de 2008.

»Comisión Económica para América Latina y el Caribe (CEPAL). Observatorio demográfico - América Latina y el Caribe (2018). Migración Internacional. Recuperado de https://www.cepal.org/es/publicaciones/44411-observatorio-demografico-america-latina-2018-migracion-internacional-demographic

»Das, V. y Poole, D. (Eds.) (2004). Anthropology in the Margins of the State. Santa Fe: SAR Press.

"Domenech, E. (2013). "Las migraciones son como el agua": Hacia la instauración de políticas de "control con rostro humano". La gobernabilidad migratoria en la Argentina. Polis-Revista Latinoamericana 12(35), 119-142. https://journals.openedition.org/ polis/9280

»Düvell, F. (2003). The Globalisation of Migration Control. Open Democracy. Recuperado de: https://www.opendemocracy.net/en/globalisation-of-migration-control

» Foucault, M. (2006). Seguridad, territorio y población. Buenos Aires: Fondo de Cultura Económica.

» Gil Araujo, Sandra (2010). Las argucias de la integración. Políticas migratorias, construcción nacional y cuestión social. Madrid: IEPALA.

" Glick Schiller, N. y Salazar, N. (2013). Regimes of Mobility Across the Globe. Journal of Ethnic and Migration Studies, 39(2), 183-200.

" Hess, S. (2012). De naturalising transit migration. Theory and methods of an ethnographic regime analysis. Population, Space and Place, 18(4), 428-440.

»Horvath, K., Amelina, A. y Peters, K. (2017). Re-thinking the politics of migration. On the uses and challenges of regime perspectives for migration research. Migration Studies, 5(3), 301-314.

" Jardim, Denise F. (2017). Imigrantes ou Refugiados? Tecnologías de Controle e as Fronteiras. Jundiaí: Paco Editorial.

»Mezzadra, S. (2012). Capitalismo, migraciones y luchas sociales. La mirada de la autonomía. Revista Nueva Sociedad, 237, 159-178.

" Odgers, O. y Campos, A. (2014). Figés dans le mouvement: périodes et espaces d'attente des migrants mexicains expulsés des Etats-Unis. Revue Européenne des Migrations Internationales, 30(2), 113-135.

»Organización de Naciones Unidas - Asamblea General (2016). Informe del Relator Especial sobre los derechos humanos de los migrantes $(A / 71 / 285)$. 
» Organización de Naciones Unidas (2016). Declaración de Nueva York para los refugiados y los migrantes (A/RES/71/1).

"Pita, M.V. y Pacecca. M.I. (Eds.) (2017). Territorios de control policial. Gestión de ilegalismos en la Ciudad de Buenos Aires. Buenos Aires: Subsecretaría de Publicaciones Facultad de Filosofía y Letras, Universidad de Buenos Aires.

" R4V, Organización Internacional para las Migraciones y Alto Comisionado de las Naciones Unidas para los Refugiados (2020). Plan Regional de Respuesta para Refugiados y Migrantes para las personas refugiadas y migrantes de Venezuela. Recuperado de https://ruv.info/es/situations/platform

"Sassen, S. (2013). Inmigrantes y ciudadanos. De las migraciones masivas a la Europa Fortaleza. Madrid: Siglo XXI.

» Sayad, A. (2008) [1984]. Estado, nación e inmigración. El orden nacional ante el desafío de la inmigración. Revista Electrónica Apuntes de Investigación del CECYP (Centro de Estudios en Cultura y Política), 13, 101-116.

"Shore, C., Wright, C. y Però, D. (Eds.) (2011). Policy Worlds: Anthropology and the Analysis of Contemporary Power. The Journal of the Royal Anthropological Institute, 19(3), 691-692.

"Trouillot, M. (2001). The Anthropology of the State in the Age of Globalization: Close encounters of the deceptive kind. Current Anthropology, 42(1), 125-138. 
